\title{
Aesthetic Rehabilitation of the Severe Bone Loss on Anterior Region Using Andrew's Bridge: A Case Report
}

\author{
Reni Puspa Daniati, Rostiny and Nike Hendrijantini \\ Department of Prosthodontic, Faculty of Dental Medicine, Universitas Airlangga, Surabaya, Indonesia
}

\begin{abstract}
A patient with several missing teeth in the anterior region usually experiences severe hard and soft tissue loss, posing a greater challenge for the prosthodontist to treat. This is a case of a 50-year-old female patient who came to the RSGMP UNAIR department of prosthodontics needing to replace the old denture that felt loose and had a change of color to rehabilitate the loss of large residual ridges involving hard and soft tissue. The patient has lost the central and lateral right maxillary incisors with severe hard and soft tissue defect after cyst removal in the region. The patient considered to restore an anterior region with severe hard and tissue loss. Andrew's Bridge successfully restores an anterior region with severe hard and soft tissue loss.
\end{abstract}

Key Words: Andrew's Bridge, fixed-removable partial dentures, bar attachment

\section{INTRODUCTION}

Tooth loss can be caused by various things including caries, periodontitis, trauma, extraction and tumor surgery. It is often followed by severe loss of alveolar bone and soft tissue around it. ${ }^{1}$ Such cases require replacing the loss of teeth and closing the defect to achieve esthetics, phonetics, and mastication. ${ }^{2}$ This defect can be fixed either with surgery or non-surgical therapy using a fixed or removable prosthesis. If the patients do not undergo surgical correction, the rehabilitation using prosthodontic is the option. Therefore, the correction of prosthodontics often becomes the chosen treatment. ${ }^{2}$

A removable partial denture (RPD) is mostly chosen for replacing several missing teeth. The RPD aims to restore the function and aesthetics needed for the patient. However, due to better aesthetics and functioning and also a specific psychological impact on the patient, most patients require a fixed prosthesis. ${ }^{3}$ However, a fixed prosthesis may not always be indicated for replacing some missing teeth when the remaining teeth in the dentition are periodontally compromised or some defects in the edentulous region are present. ${ }^{3}$

Dr. James Andrews of Amite, Louisiana, USA,

Paper presented at the Joint Scientific Meeting in Special Care Dentistry, July 5, 2019, Amerta Room, 4th Floor, main campus of Universitas Airlangga, Surabaya, Indonesia.

Corresponding author: Nike Hendrijantini

Department of Prosthodontic

Faculty of Dental Medicine

Universitas Airlangga

JI. Mayjen. Prof. Dr. Moestopo No. 47 Surabaya 60132 - Indonesia

Email: nike-h@fkg.unair.ac.id introduced the fixed-removable prosthesis in 1965 when fixed denture or removable partial denture failed to treat ridge defects. The fixed-removable prosthesis is called Andrew's Bridge which consists of a fixed retainer and removable pontics. ${ }^{1}$ The fixed component consists of porcelain fused to metal crowns which are joined to the prepared abutments by cast bar cemented on. The removable component consists of 
acrylic teeth on an acrylic base that is embedded in metal or plastic sleeve tract. ${ }^{3}$

The indications for fixed-removable Andrew's Bridge system are tooth loss along with the defect in the edentulous ridge, failure of fixed partial denture because of long edentulous space, the removable partial denture has failed due to discomfort related to its palatal extension. ${ }^{3}$

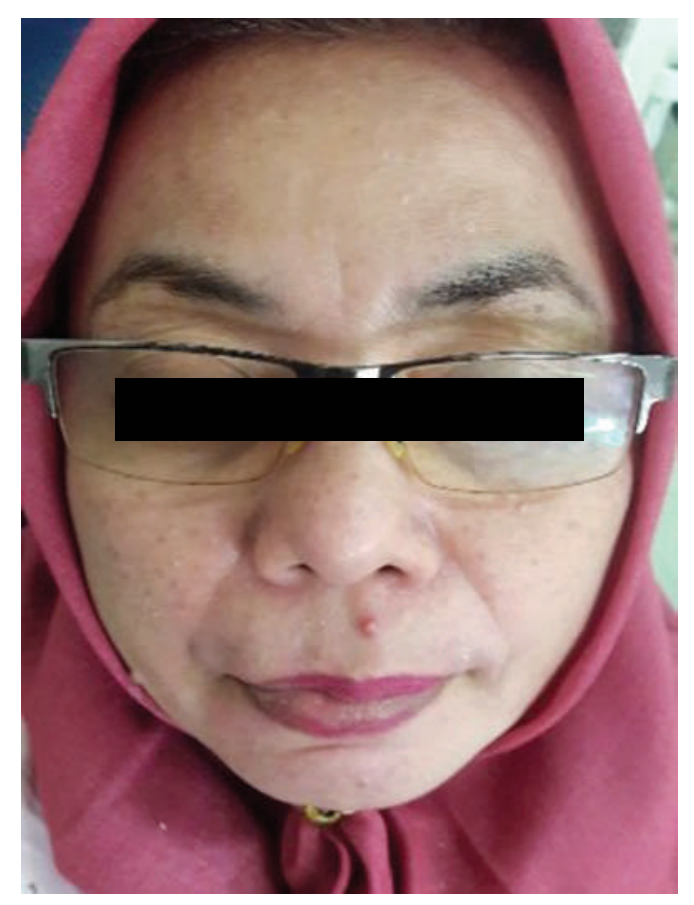

Figure 1. Reduced upper lip.
This case report describes the correction of tooth loss and defects using fixed-removable Andrew's bridge system wherein a removable prosthesis is retained by a bar and sleeve attachment to fixed retainers on either side of the edentulous space. Andrew's Bridge is designed to fulfill the requirements for aesthetics, hygiene, comfort, phonetics, and favorable stress distribution to the abutments and soft tissue.

\section{CASE REPORT}

A 50-year-old female patient came to the RSGMP UNAIR department of prosthodontics on her own desire to replace the old denture that felt loose and had a change of color. A complete medical and dental history was obtained. The patient lost the central and lateral right maxillary incisors with severe hard and soft tissue loss post cyst surgery in that region 10 years before.

Extraoral examination of the face, eyes, nose, and lips have no abnormalities but revealed reduced upper lip support. (Figure 1) Ruled out temporomandibular disorder. Intraoral examination revealed following missing teeth: $11,12,27,36,46$. Anterior deep bite $(7 \mathrm{~mm})$ and protrusive $(7 \mathrm{~mm})$ were present (Figure 2). There was a considerable reduction in the height and width of the residual alveolar ridge in the maxillary anterior region (Sieberts Classification Class III). Panoramic radiographs were made. The radiographs showed good bone support around the abutment teeth $(13,21)$ (Figure 3$)$.

Some options were given to the patient such as a fixed partial denture or removable partial denture or fixedremovable partial denture. The patient chose a fixed partial
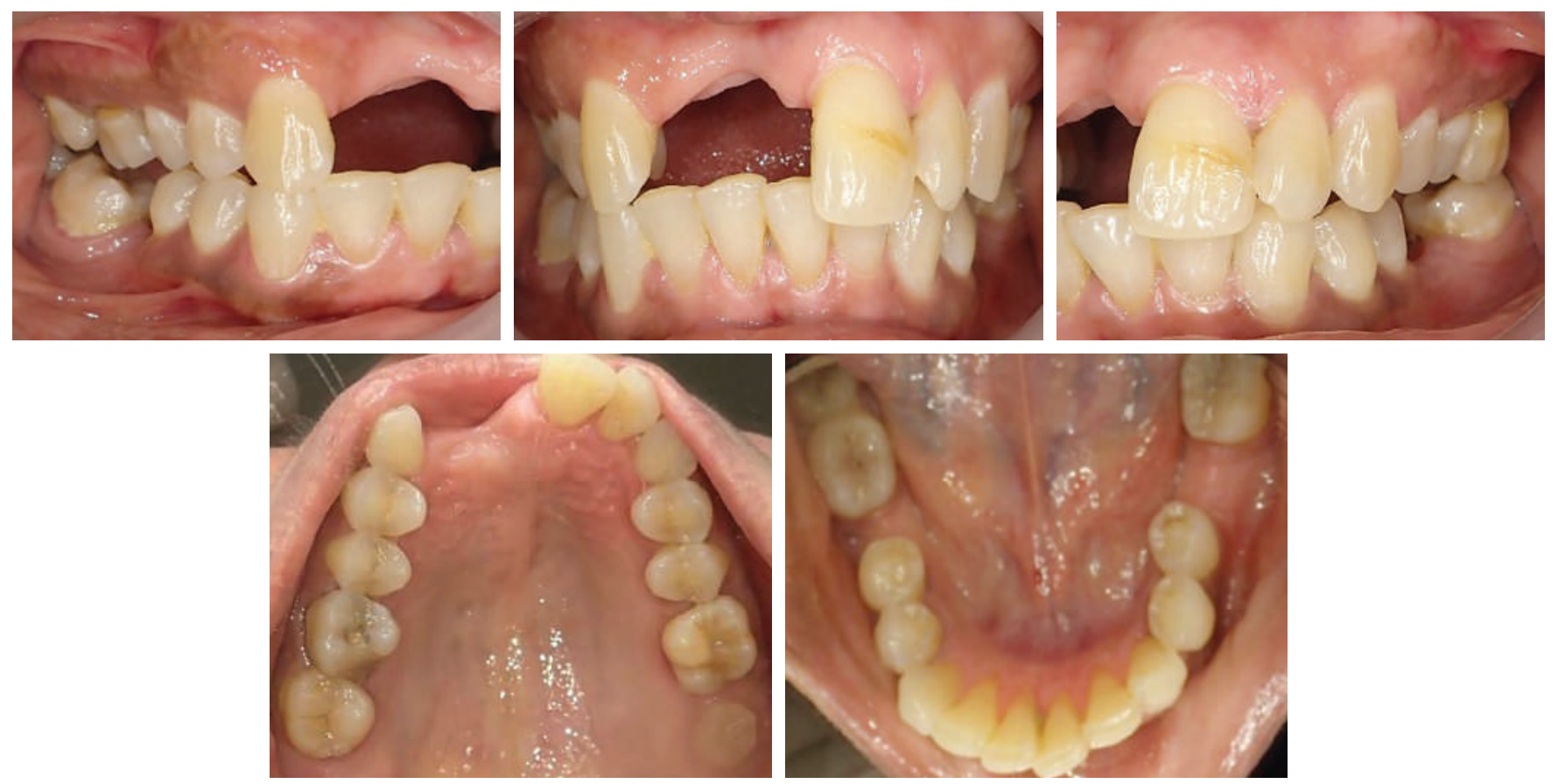

Figure 2. Pre-operative condition of patient's teeth. 


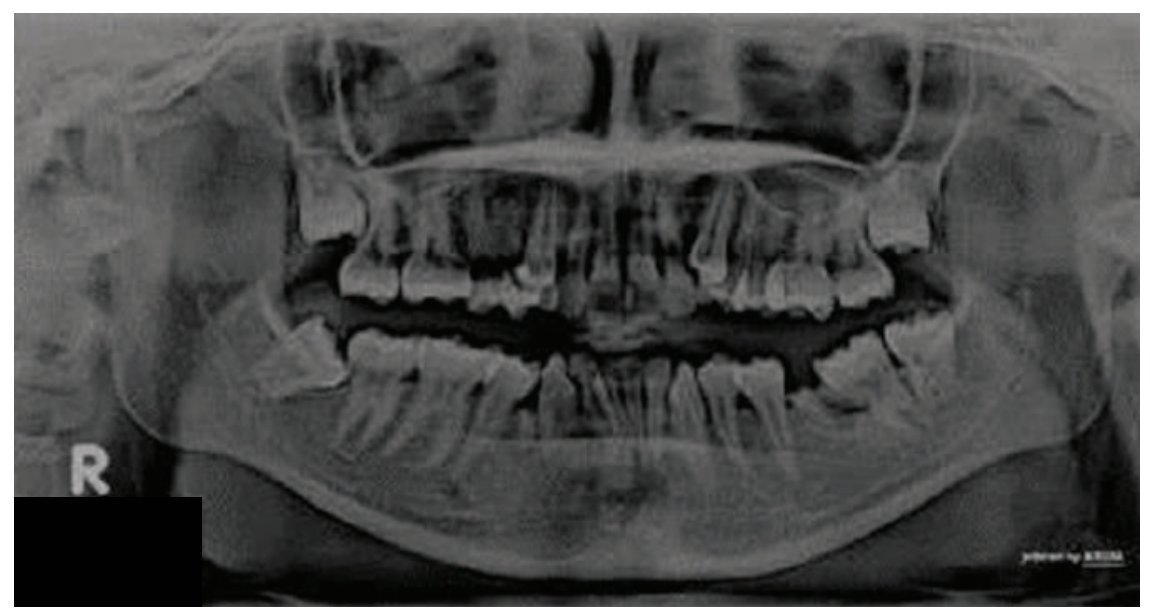

Figure 3. Panoramic radiograph of patient's teeth.

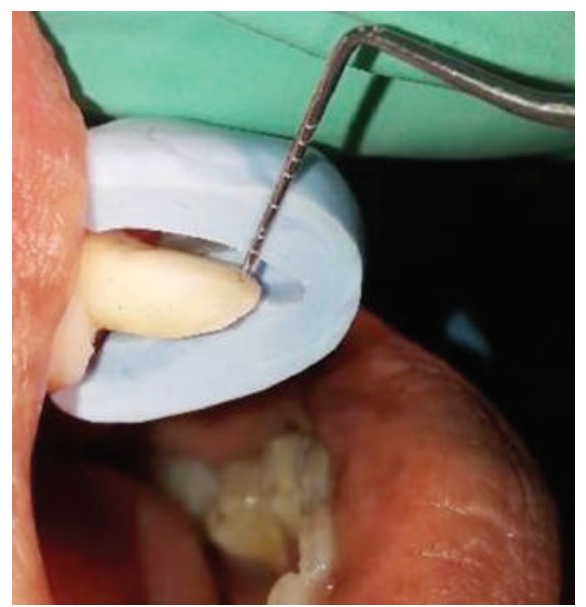

Figure 4. Assessment of the preparation with putty indeks.

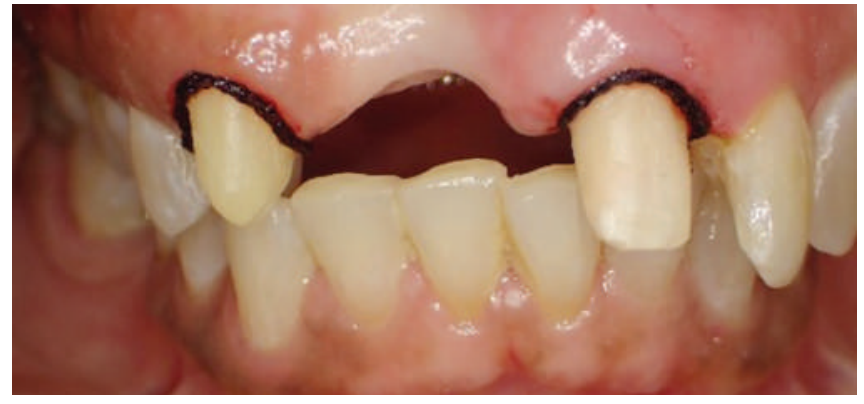

Figure 5. After the preparation the gingival retraction was done using chemico-mechanical method.

denture for aesthetic and comfort reasons, but a fixed partial denture was required to restore bone defect and the patient refused it because the surgery was complex. Complications and failures can often occur after bone augmentation procedures. These techniques are not completely predictable and are not always able to guarantee the expected result. Therefore, conventional fixed partial denture was excluded from the treatment options. The patient also refused removable partial dentures because the claps can reduce aesthetics in the anterior region. In the end, the patient chose fixedremovable partial denture Andrew's Bridge because it has the advantages of both removable and fixed partial denture and it was advantageous. Removable partial denture acrylic was used for missing teeth in the posterior region of mandible.

\section{CASE MANAGEMENT}

Andrew's Bridge was planned in the maxillary arch and removable partial denture acrylic was planned for mandibular arch. This case focused on treatment for the maxillary arch using Andrew's Bridge. The missing left maxillary second molar was not replaced because the space was too small and did not affect occlusion. The initial treatment was done by removing dental calculus after the diagnostic impression

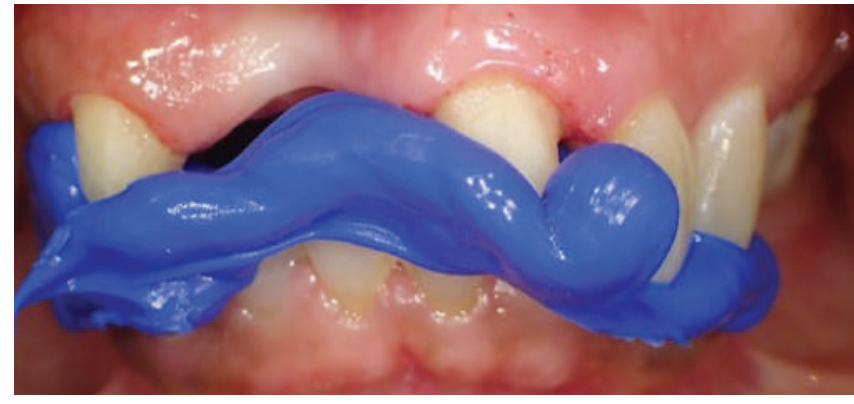

Figure 6. Bite registration.

of the maxillary and mandibular arches were made by irreversible hydrocolloid impression material, and study casts were poured. The casts were mounted on an articulator.

Right maxillary canine and left central incisor on the other side were chosen as abutments to support Andrew's Bridge. Diagnostic wax-up was done in such a way that it would close the defect and restore aesthetics, to preview the final outcome using a composite mock-up in the patient. A precise mock-up is the best way for the dentist and the patient to get a preview of the aesthetic and functional outcome of a case.

The operator made a putty index form the final mockup as a guideline for preparation thickness. The abutment teeth 13 and 21 were prepared to receive Porcelain fused to metal (PFM) crowns because the patient had a deep bite so the crown designed with a metal contact on the palatal surface. To check the results of the preparation, putty index that has been made before was used (Figure 4). Once the preparation was finished, the gingival retraction was done using chemico-mechanical method (Figure 5), and the final impressions used double impression, polysiloxane and light body impression. After that, a bite registration was taken (Figure 6) and a temporary crown was made and temporary cement was inserted. 


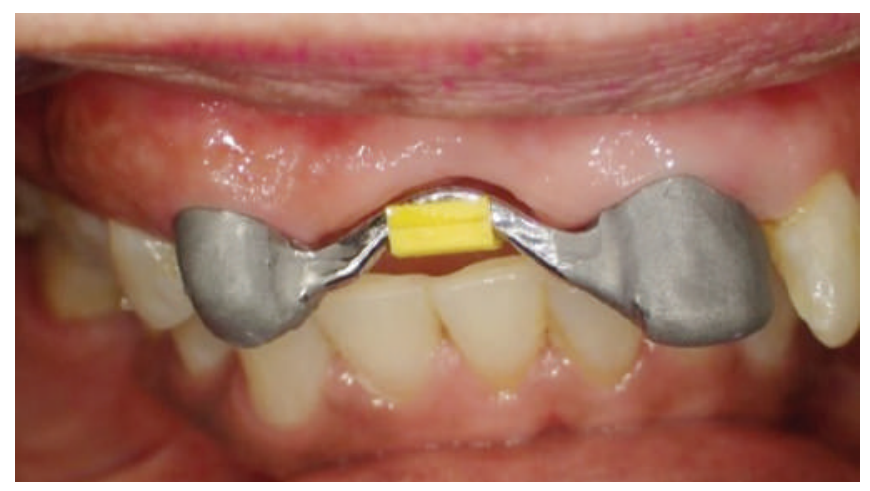

Figure 7. Try-in of metal crown with bar.

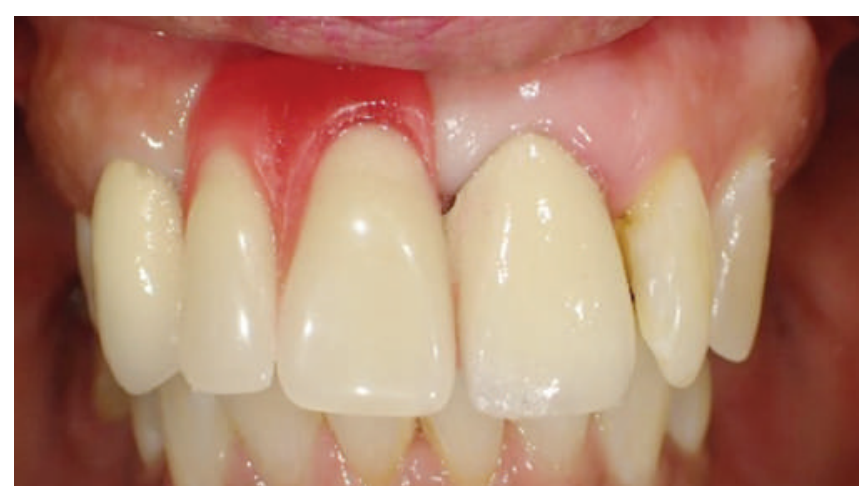

Figure 8. PFM and wax try-in.

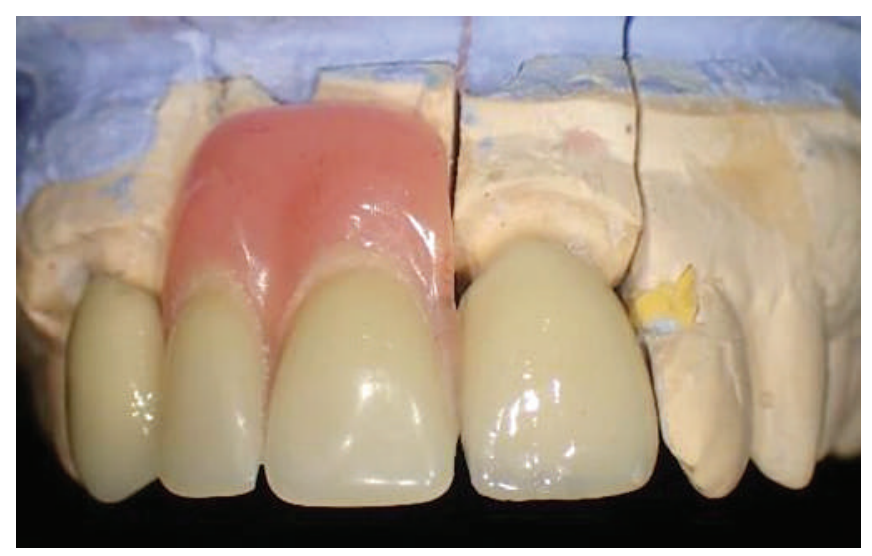

Figure 9. Andrew's Bridge on model.
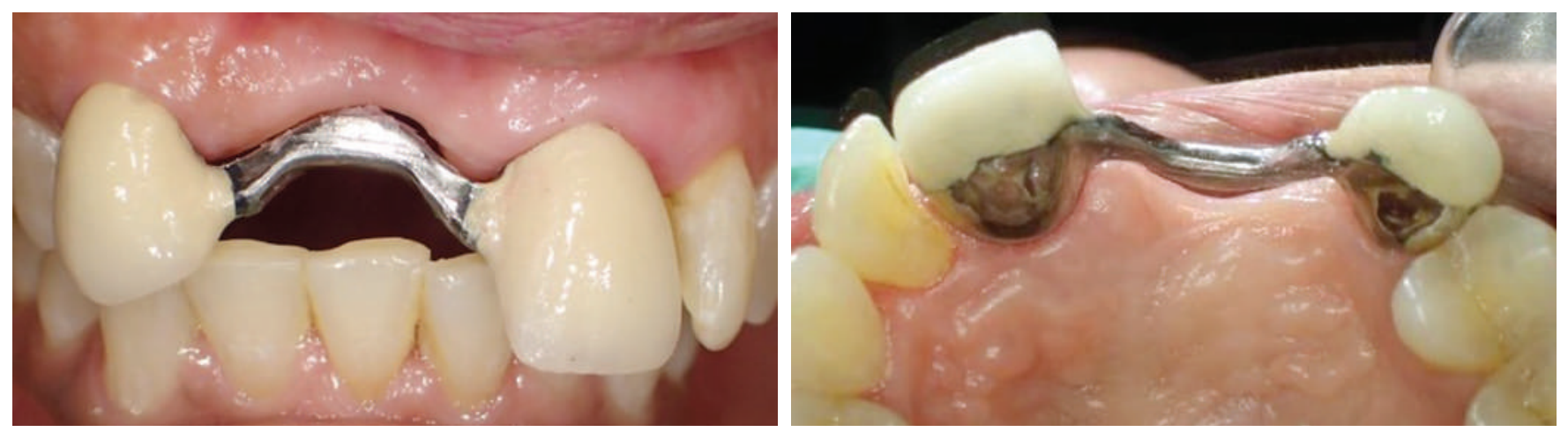

The master casts were poured using Type-IV gypsum products and were mounted on an articulator and sent to the laboratory. The next step was metal coping and bar try in for the maxillary prosthesis (Figure 7). The operator checked the occlusion, fitting, and the position of bar was located such that 2-3 $\mathrm{mm}$ of space on the left between the bar and the crest of the alveolar ridge to facilitate maintenance of hygiene by the patient. Shade selection was done with vita shade guide and the A3 VITA Shade Guide was chosen. Bite rim was made from hard sheet wax in the pontic area, then the patient was trained to open and close her mouth to achieve appropriate occlusion.

The ceramic build-up was done for the PFM Bridge. Waxed up trial denture replacing 11, 12 was fabricated and adjusted to match the facial midline of the patient (Figure 8). Wax was added to the labial portion of the denture flange for adequate lip support and esthetics, and then the waxed up trial denture was processed in heat cure acrylic resin, finished and polished and tried in patients mouth over the fixed component of the Andrew's Bridge system (Figure 8). The clip was attached to the bar attachment and was picked up in self-cure acrylic resin into the RPD. The denture was removed, finished, and polished and it was checked for retention of the bar and clip, esthetics, and phonetics. The fixed retainer part of the Andrew's Bridge system was cemented over the prepared teeth with glass ionomer cement (Figures 9-11).

The patient was trained to place and remove the removable pontic. The use of interdental brush under the bar attachment was suggested for the maintenance of oral hygiene along with routine oral hygiene instructions. The patient was also advised to have a regular control: control I (one day after insertion), control II (three days after insertion), and control III (seven days after insertion) and the periodic recall was emphasized to check for the success of the treatment.

For mandibular arch preparation mesial rest on hydrocolloid impression material, and study casts were poured with type III hard gypsum. Mandibulary working 37,47 , the impression material was taken by irreversible

Figure 10. Insertion of Andrew's Bridge. 


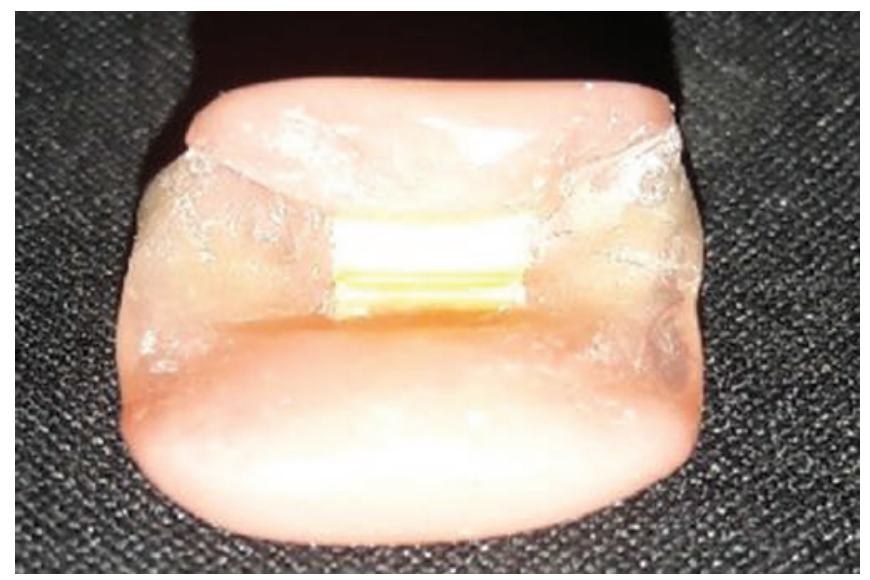

Figure 11. Clip attachment in removable partial denture.
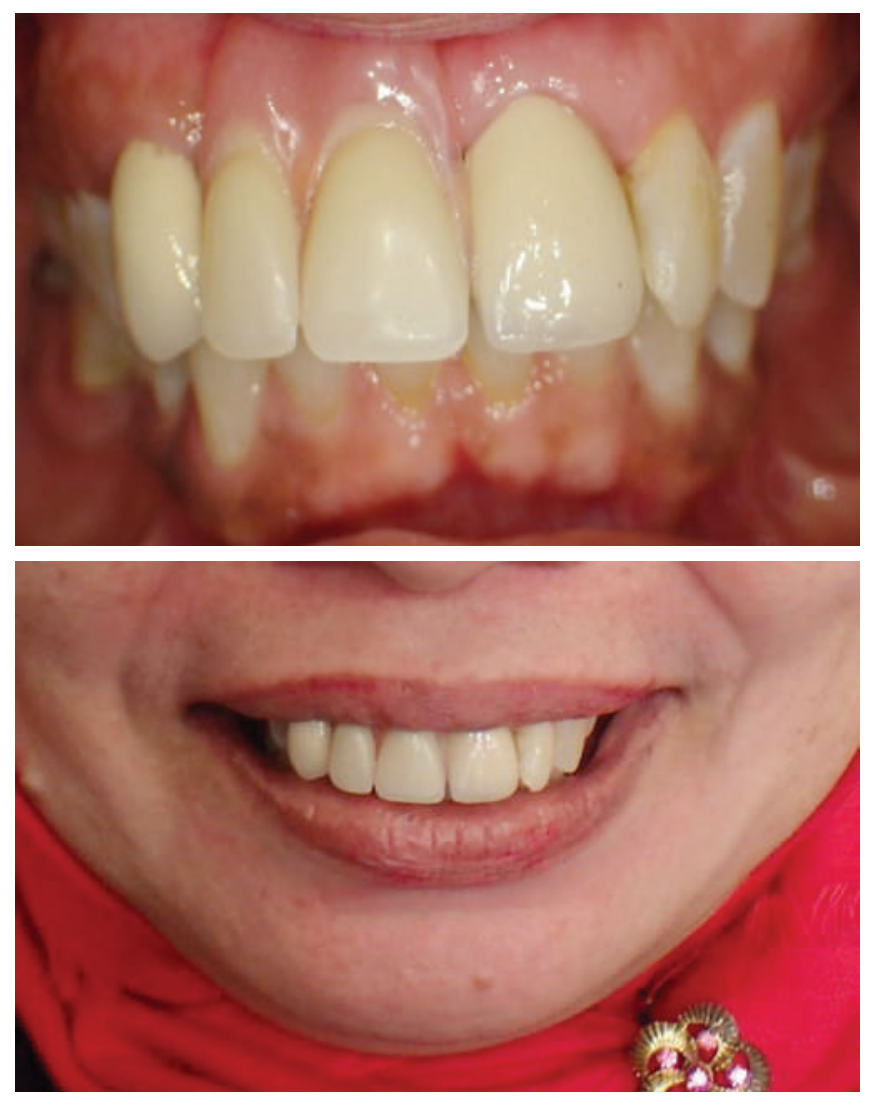

Figure 12. Post-operative intra- and extraoral cavity.

model was sent to the laboratory and making claps half Jackson on 35,45 and 3 jari on 37,47 . Bite rim was made, then the patient was trained to open and close her mouth before to achieve appropriate occlusion. The choice of tooth color was approved A3 VITA Shade Guide. After that, processing acrylic in the lab and then finishing and polishing processes were performed, removable partial denture mandibular was adjusted in patient's mouth. The evaluation was done on aesthetic performance, occlusion, and stability. The patient was also advised to have a regular control: control I (one day after insertion), control II (three days after insertion), and control III (seven days after insertion).

\section{DISCUSSION}

Alveolar bone loss is reported in many cases accompanying loss of anterior teeth. Only $9 \%$ of patients had almost no ridge defects. The most common defects are the combined Class III defects ( $56 \%$ of cases) followed by Class I horizontal defects (33\% of cases) and vertical defects were found in $3 \%$ of cases. ${ }^{4}$

Rehabilitation of aesthetic, comfort, and function should be the major focus of oral rehabilitation. The prosthetic options for replacement of missing anterior teeth are conventional fixed partial dentures, removable partial dentures, implant-supported fixed prostheses, and fixed removable partial denture "Andrew's Bridge". ${ }^{5}$

A fixed bridge or implant sometimes cannot be used in severe hard and soft tissue loss. Surgical correction of the defects using grafts is complex and expensive treatment plan for some patients. ${ }^{4}$

The removable partial denture is a worthy treatment option that can be proven successful in restoring function, aesthetics, speech, and closure of defects, but the require claps can reduce aesthetics when it replaces the lost structures and becomes heavy and less comfortable. ${ }^{2}$

The Andrew's Bridge system is one of the treatments that can provide maximum aesthetic and phonetic optimality in cases involving loss of soft and hard tissue. "Andrew's Bridge" is a combination of a fixed dental prosthesis that incorporates a bar with a removable dental prosthesis that replaces teeth within the bar area, usually used for edentulous anterior spaces. The vertical walls of the bar providing retention for the removable component of the Andrew's Bridge were developed when all the conventional methods of replacement were not successful in treating severely resorbed residual ridge, in order to achieve comfort, hygiene, optimum phonetics, and maximum esthetics. ${ }^{4}$

The major advantage of the Andrew's system is that the pontic assembly can be removed to facilitate hygiene procedures and may be relined when the ridge resorbs. The fixed-removable partial denture is more stable compared to a conventional RPD because it is tooth-borne, and the occlusal forces are directed more along the long axes of the abutment teeth. ${ }^{1}$

Compared to a fixed dental prosthesis, the pontic teeth are arranged during the esthetic try-in appointment. The flange of the pontic can be contoured to improve esthetics, comfort, and phonetics, and to resist torque during function. Replacement of the teeth along with an acrylic denture flange is an added advantage as it does not require a separate prosthesis for the gingival defect as in the FDP. Since the prosthesis is retained by a bar retainer, the normal perception of taste is maintained as the flange need not be extended palatally for support. ${ }^{6}$ 
When conventional removable partial denture or fixed partial denture wasn't the right option for them, a third treatment option of Andrew's Bridge can prove successful in restoring esthetics, function, speech and defect closure. Limited reports on the failure of Andrew's Bridge are found in the literature. The failures are mainly due to inadequate soldering which can be avoided by attaching retainers to the bar in a single casting. ${ }^{1}$

\section{CONCLUSION}

Andrew's Bridge successfully restores an anterior region with severe hard and soft tissue loss. Andrew's Bridge allows rehabilitation of several missing teeth in the anterior aesthetic region with severe hard and soft tissue loss. Andrew's Bridge is designed to fulfill the requirements for aesthetics, hygiene, comfort, phonetics, and favorable stress distribution to the abutments and soft tissue. The patient was found to be comfortable with the prosthesis without any complaint and showed improved esthetics and phonetics. Andrew's Bridge which has qualities of both the fixed partial denture and the removable partial denture can be indicated in cases where the abutments would support a fixed partial denture but a severe defect is present in the edentulous space.

\section{Statement of Authorship}

All authors participated in data collection and analysis, and approved the final version submitted.

\section{Author Disclosure}

All authors declared no conflict of interest.

\section{Funding Source}

None.

\section{REFERENCES}

1. Bhapkar P, Botre A, Menon P, Gubrellay P. Andrew's Bridge System: An Esthetic Option. J Dent Allied Sci. 2015; 4:36-40.

2. Jain AR, Hemakumar V, Janani T. Rehabilitation of Sieberts Class Iii Defect Using Fixed Removable Prosthesis (Andrew's Bridge): A Case Report. J Pharm Sci Res. 2016; 8(9):1045-9.

3. Tambe A, Patil SB, Bhat S, Badadare MM. Andrew's Bridge system : an aesthetic and functional option for rehabilitation of compromised maxillary anterior dentition. BMJ Case Rep. 2014; 2014.

4. Rai R, Menaga V, Prabu R Geetha KR, Suprabha R. A prosthodontic management of severely resorbed anterior ridge defect - a case report. J Clin Diagn Res. 2014; 8(9):ZD15-7.

5. Saumyendra SV, Gaurav B, Varun B, Kumar SK, Kamleshwar S, Deeksha A. Full mouth rehabilitation with modified Andrew's Bridge following Le Fort osteotomy for a patient with maxillary retrognathia. J Dent Oral Disord. 2017;3(2):1058.

6. Patel H, Solanki P, Patel S, Patel U. Management of anterior ridge defect with fixed-removable partial denture - Andrew's Bridge. J Dent Med Sci. 2015; 14(8):19-22. 